\title{
FRANGOS DESAFIADOS EXPERIMENTALMENTE COM Salmonella enterica SOROVAR ENTERITIDIS E Eimeria tenella E TRATADOS COM ÁCIDOS ORGÂNICOS
}

\section{CHICKENS CHALLENGED AGAINST Salmonella enterica SOROVAR ENTERITIDIS AND Eimeria tenella AND TREATED WITH ORGANIC ACIDS}

\author{
Gracinda Mariana Calaça1 ORCID http://orcid.org/ 0000-0001-5593-612X \\ Marcos Barcellos Café ${ }^{1}$ ORCID http://orcid.org/0000-0002-1478-8009 \\ Maria Auxiliadora Andrade1 ORCID http://orcid.org/0000-0002-8373-1671 \\ José Henrique Stringhini ${ }^{1}$ ORCID http://orcid.org/0000-0002-3710-6963 \\ Itallo Conrado Sousa Araújo ${ }^{*}$ ORCID http://orcid.org/0000-0001-8882-3180 \\ Nadja Susana Mogyca Leandro ORCID http://orcid.org/0000-0002-6525-9975 \\ 1 Universidade Federal de Goiás, Goiânia, GO, Brasil. \\ 2 Universidade Federal de Minas Gerais, Belo Horizonte, MG, Brasil. \\ *Autor para correspondência - italloconradovet@hotmail.com
}

\section{Resumo}

Foi avaliado um composto comercial de ácidos orgânicos, adicionado à ração, no controle da Salmonella de frangos de corte desafiados com Salmonella Enteritidis e Salmonella Enteritidis associadas à Eimeria tenella. Foram utilizados 504 pintos de um dia, fêmeas, da linhagem Hubbard ${ }^{\circledR}$, sendo o delineamento inteiramente casualizado em esquema fatorial $2 \times 3$, totalizando seis tratamentos com seis repetições e 14 aves a unidade experimental. Foi analisado o pH intestinal, o escore de lesão dos cecos, contagem de oocistos fecais e a presença de salmonela no baço e tonsilas cecais das aves. Aves desafiadas com S. Enteritidis que receberam ácidos apresentaram menor frequência de isolamento da bactéria nos órgãos linfoides analisados. Assim como apresentaram redução no número de oocistos de E. tenella nas excretas coletadas diretamente na bandeja e redução dos escores de lesão intestinal provocadas pela infecção por Eimeria tenella. Os ácidos orgânicos promoveram benefício à saúde intestinal dos frangos de corte com reflexos positivos no controle da Salmonella Enteritidis juntamente com a Eimeria tenella.

Palavras-chave: coccidiose, intestino delgado, microbiologia

\begin{abstract}
A commercial organic acids compound was assessed, added to feed, to control Salmonella Enteritidis. Broilers were challenged with Salmonella Enteritidis and Salmonella Enteritidis associated with Eimeria tenella. Five hundred and four day-old Hubbard ${ }^{\circledR}$ females chicks were used in a completely randomized design in a $2 \times 3$ factorial, a total of six treatments with six replications and being 14 birds the experimental unit. Intestinal $\mathrm{pH}$, cecum lesion score, oocyst faecal counts and the presence of
\end{abstract}


Salmonella in the cecal tonsils and spleen of broilers were investigated. Broilers that were challenged only with $S$. Enteritidis that received the compound in test showed lower frequency of bacteria isolation in lymphoid organs. Besides, decreased number of oocysts of E. tenella was observed and the intestinal lesion scores caused by infection was lower. Organic acids promoted a benefit on broilers intestinal health with positive effects on the control of Salmonella Enteritidis with Eimeria tenella.

Keywords: coccidiosis, microbiology, small intestine

Recebido em: 1 de setembro de 2016.

Aceito em: 2 de abril de 2019

\section{Introdução}

A Salmonella Enteritidis (SE) é o patógeno entérico, pertencente à família Enterobacteriaceae, de origem alimentar, mais frequentemente distribuído na natureza em diferentes espécies animais e, em frangos de corte, pode resultar severas perdas econômicas, devido aos altos custos com erradicação e medidas de controle ${ }^{(1)}$. Ainda, de acordo com Andrade et al. ${ }^{(2)}$, quando pintos neonatos estão contaminados com a Salmonella Enteritidis sofrem injurias intestinais, que pioram o desempenho das aves.

Uma forma de tratamento para as salmoneloses no Brasil, visando amenizar seus efeitos sobre o trato gastrintestinal das aves, é o uso de antimicrobianos melhoradores de desempenho nas rações, uma vez que ainda não foram proibidos de serem utilizados no país. Entretanto, o uso desses fármacos nas rações tem sido proibido em países europeus desde 2003 e essa proibição está relacionada a diversos fatores, dentre eles: à seleção de microrganismos resistentes, ao desenvolvimento de resistência bacteriana cruzada em humanos e à exigência de produtos livres de resíduos de antibióticos pelo mercado consumidor ${ }^{(3)}$. A retirada dos antibióticos promotores de crescimento da dieta de frangos leva à diminuição média no desempenho das aves com impacto negativo sobre saúde animal e aumento na mortalidade das aves, gerando prejuízos econômicos ${ }^{(4)}$.

Outro problema entérico que acomete frangos de corte em produção industrial são as eimeirioses. Apesar da grande oferta de medicamentos anticoccídicos, as eimerioses ainda causam grandes prejuízos para a avicultura mundial ${ }^{(5)}$. Esses protozoários são responsáveis por pior desempenho dos animais e, consequentemente, perdas econômicas ${ }^{(6)}$. O uso indiscriminado de anticoccídicos tem resultado na seleção de cepas resistentes a drogas, as quais reduzem a eficácia de vários desses medicamentos que estão em uso ${ }^{(7)}$. Além disso, tem ocorrido uma mudança comportamental do consumidor, o qual tem procurado cada vez mais produtos produzidos sem a utilização de agentes químicos ${ }^{(8)}$.

Nesse contexto, os ácidos orgânicos surgem como alternativa de controle de injúrias intestinais, causadas por desafios bacterianos. De acordo com Pickler et al. ${ }^{(9)}$, um dos métodos de controle da salmonelose em frangos é a adição de ácidos orgânicos na ração e água dos animais, pois os ácidos alteram o pH intestinal das aves, passando a ter uma ação antibacteriana, particularmente contra bactérias Gram Negativas.

Diante do exposto, objetivou-se avaliar o efeito de um composto de ácidos orgânicos (propiônico, 
acético e fórmico) associados a um carrier mineral como veículo adicionado à ração no controle de enterites causadas por salmoneloses e eimerioses em frangos de corte experimentalmente desafiados com $S$. Enteritidis ou $S$. Enteritidis associada à Eimeria tenella sobre aspectos clínico-patológicos, análises microbiológicas e parasitológicas.

\section{Material e métodos}

O experimento foi aprovado pelo comitê de ética em pesquisa animal da Universidade Federal de Goiás (Protocolo 138/08). Foram utilizados 504 pintos de corte de um dia, fêmeas, da linhagem comercial HUBBARD, com peso médio inicial de 40,3 g, oriundos de um incubatório comercial que realizava monitoramento para Salmonella, estando assim as aves livres de patógenos no início do experimento. Os tratamentos utilizados foram distribuídos em delineamento inteiramente ao acaso em esquema fatorial 3x2 (presença de desafio com Salmonella Enteritidis e Eimeria tenella, Salmonella Enteritidis isolada ou sem nenhum desafio x adição ou não dos ácidos orgânicos na ração), totalizando seis tratamentos com seis repetições cada, sendo 14 aves a unidade experimental.

A dieta fornecida às aves foi ração vegetal farelada a base de milho moído e farelo de soja, formulada de acordo com Rostagno et al. ${ }^{(10)}$ sendo isoprotéicas e isoenergéticas. Produtos anticoccidianos e aditivos antimicrobianos não foram adicionados à ração. $\mathrm{O}$ composto de ácidos orgânicos (acético, fórmico e propiônico) foi adicionado somente às rações dos tratamentos com adição dos ácidos orgânicos, na concentração de $4 \mathrm{~kg}$ do aditivo por tonelada de ração, sendo que ele contém: ácido acético (5\%), ácido fórmico (12\%) e ácido propiônico (4\%).

As aves dos tratamentos desafiados com Salmonella Enteritidis foram inoculadas por via oral no primeiro dia de vida e com reforço aos sete dias de vida, com 0,3 $\mathrm{mL}$ de solução salina tamponada estéril a 0,85\% contendo 4,8 x 106 unidades formadoras de colônias (UFC) de SE por dose de 0,3 $\mathrm{mL}$. As aves dos tratamentos desafiados com Eimeria tenella $(\mathrm{Et})$ foram inoculadas por via oral com 15 dias de vida com uma concentração de 105 oocistos/ave. As aves do grupo controle foram monitoradas com coleta por meio de suabe de cloaca e realizada pesquisa da presença da Salmonella spp nos dias um, sete, 14, 21, 28 e 35 do período experimental, sendo coletada amostra de duas aves por parcela ao acaso. Houve negatividade da presença da bactéria para todos as coletas.

As aves foram alojadas em baterias de aço galvanizado acomodadas em duas salas de alvenaria, cujos ambientes de criação eram isolados e controlados, com separação física entre os tratamentos desafiados e os não desafiados.

Para a avaliação do pH intestinal e cecal, os conteúdos do intestino delgado e cecos foram coletados, diluídos em $15 \mathrm{~mL}$ de água destilada, homogeneizados e determinado o $\mathrm{pH}$ (utilizando-se peagâmetro digital), conforme metodologia descrita por Silva et al. ${ }^{(11)}$.

Para a pesquisa da presença da Salmonella Enteritidis, foi realizada eutanásia de uma ave por repetição nas idades de 14, 21, 28 e 35 dias e coletado o baço e tonsilas cecais (totalizando seis aves por tratamento). O método de eutanásia das aves empregado neste experimento foi pela aplicação de cloridrato de lidocaína a $2 \%$ por via intratecal. Imediatamente após a coleta do baço e tonsilas cecais, 0,5 $\mathrm{g}$ da amostra foi macerada, homogeneizada e colocada em tubos de ensaio contendo 4,5 $\mathrm{mL}$ de caldo de enriquecimento Selenito-Cistina e incubados em estufa a $37{ }^{\circ} \mathrm{C}$ por 24 horas. Dos caldos de enriquecimento, alíquotas foram repicadas nos ágares Hektoen, Rambach e XLT4 para microbiologia. A pesquisa de $S$. Enteritidis foi realizada de acordo com GEORGIA $^{(12)}$ e BRASIL ${ }^{(13)}$, com as 
modificações propostas por Andrade et al. ${ }^{(14)}$.

Para cada um dos ágares, foram selecionadas quatro colônias com características morfológicas sugestivas da salmonela e transferidas para Agar tríplice açúcar-ferro (ágar TSI), seguindo-se incubação a $37^{\circ} \mathrm{C}$ por 24 horas. Os isolados bacterianos que apresentaram reações e características compatíveis às do gênero Salmonella foram submetidas aos testes bioquímicos de produção de indol, produção de $\mathrm{H}_{2} \mathrm{~S}$, urease, descarboxilação da lisina, vermelho de metila e utilização do malonato e motilidade.

Os tubos dos testes bioquímicos foram incubados a $37^{\circ} \mathrm{C}$ por até sete dias, com leituras diárias para as provas com resultados negativos nas primeiras 48 horas de incubação e para os testes de descarboxilação ou hidrólise de aminoácidos. As amostras confirmadas bioquimicamente como SE foram ainda submetidas a testes sorológicos com soro polivalente anti "O". Aquelas confirmadas na bioquímica e na sorologia foram encaminhadas ao Instituto Osvaldo Cruz (FIOCRUZ-RJ) para tipificação sorológica.

Para avaliar o desenvolvimento da coccidiose, foi realizada a contagem de oocistos de Eimeria tenella e, também, a avaliação macroscópica dos cecos. A contagem de oocistos foi feita aos cinco, seis, sete, oito, nove, 10 e 11 dias após a inoculação dos oocistos de Eimeria tenella, sendo colhidas $10 \mathrm{~g}$ de amostra de excretas diretamente de cada uma das bandejas coletoras de excretas, sendo coletadas em quatro pontos distintos da bandeja. As amostras foram armazenadas em frascos plásticos e colocadas sob refrigeração $\left(8^{\circ} \mathrm{C}\right)$, processadas (obtendo-se um pool de cada parcela) ao final do experimento, a realização da contagem de oocistos foi realizada seguindo-se o método de McMaster, conforme descrito por Kazowue ${ }^{(15)}$.

Ainda foi realizada eutanásia de uma ave por repetição (totalizando seis aves por tratamento), aos 21 dias de vida, para realização da necropsia e determinação do grau de lesão macroscópica dos cecos, sendo avaliada de acordo com os escores de lesão cecal ${ }^{(16)}$.

A análise estatística foi realizada seguindo o esquema da Análise de Variância (ANOVA), para um delineamento inteiramente ao acaso em esquema fatorial $3 \times 2$. O programa utilizado foi SAS ${ }^{(17)}$, e foram adotados para comparação entre as médias o teste de Tukey (variáveis quantitativas) e KruskalWallis (variáveis qualitativas).

\section{Resultados e discussão}

Os resultados de pH intestinal nos períodos de um a 14, 21, 28 e 35 dias de idade (Tabela 1) apontam que não houve interação significativa $(\mathrm{P}>0,05)$ entre os grupos estudados. Ainda, não houve efeito da inoculação dos microrganismos para o pH do intestino delgado $(\mathrm{P}>0,05)$ aos 14 e 21 dias de idade das aves. Foi possível observar diferenças para valores de $\mathrm{pH}$ de intestino aos 28 e 35 dias de idade $(\mathrm{P}<0,05)$, sendo que, aos 28 dias de vida, o intestino das aves pertencentes ao tratamento controle apresentou $\mathrm{pH}$ maior que o grupo inoculado com ambos os microrganismos.

Já para 35 dias de vida, o pH do intestino foi menor no grupo controle quando comparado ao grupo inoculado somente com a salmonela. Sendo assim, provavelmente as alterações de pH não estejam associadas aos desafios, pois a variação de $\mathrm{pH}$ manteve-se dentro do padrão para frangos de corte de acordo com Morgan et al. ${ }^{(18)}$ : varia de 6,0 a 7,5 no intestino delgado e 6,5 a 8,0 nos cecos. 
Tabela 1. Valores de $\mathrm{pH}$ do intestino delgado e cecos aos 14, 21, 28 e 35 dias de idade em frangos de corte desafiados via oral com Salmonella Enteritidis e Eimeria tenella via oral e tratados com ração contendo ácidos orgânicos

\begin{tabular}{|c|c|c|c|c|}
\hline \multirow[b]{2}{*}{ Tratamento } & \multicolumn{4}{|c|}{ Intestino delgado $(\mathrm{pH})$} \\
\hline & 14 dias & 21 dias & 28 dias & 35 dias \\
\hline \multicolumn{5}{|l|}{ Desafio } \\
\hline Controle & 6,77 & 6,54 & $6,76 \mathrm{a}$ & $6,36 \mathrm{~b}$ \\
\hline Salmonella & 6,79 & 6,47 & $6,55 \mathrm{ab}$ & $6,57 \mathrm{a}$ \\
\hline Salmonella + Eimeria & 6,90 & 6,27 & $6,54 b$ & $6,46 \mathrm{ab}$ \\
\hline \multicolumn{5}{|l|}{ Ácidos orgânicos } \\
\hline Sem ácidos & $6,89 a$ & 6,48 & 6,66 & 6,48 \\
\hline Com ácidos & $6,75 b$ & 6,38 & 6,57 & 6,45 \\
\hline $\mathrm{CV}(\%)$ & 2,59 & 7,22 & 3,38 & 3,13 \\
\hline \multicolumn{5}{|l|}{ Valor de P } \\
\hline Desafio & NS & NS & 0,020 & 0,045 \\
\hline Ácido & 0,020 & NS & NS & NS \\
\hline \multirow[t]{2}{*}{ Desafio $x$ ácido } & NS & NS & NS & NS \\
\hline & \multicolumn{4}{|c|}{$\operatorname{Cecos}(\mathrm{pH})$} \\
\hline Tratamento & 14 dias & 21 dias & 28 dias & 35 dias \\
\hline \multicolumn{5}{|l|}{ Desafio } \\
\hline Controle & $6,66 b$ & 6,60 & 6,98 & $6,55 b$ \\
\hline Salmonella & $7,00 \mathrm{a}$ & 6,83 & 6,98 & $6,87 \mathrm{a}$ \\
\hline $\begin{array}{l}\text { Salmonella + Eimeria } \\
\text { Ácidos orgânicos }\end{array}$ & $7,07 \mathrm{a}$ & 6,75 & 6,89 & $7,00 \mathrm{a}$ \\
\hline Sem ácidos & 6,97 & 6,97 & 6,92 & 6,79 \\
\hline Com ácidos & 6,85 & 6,79 & 6,98 & 6,83 \\
\hline $\mathrm{CV}(\%)$ & 3,07 & 5,11 & 5,85 & 4,30 \\
\hline \multicolumn{5}{|c|}{$\mathrm{P}$} \\
\hline Desafio & 0,0001 & NS & NS & 0,0021 \\
\hline Ácido & NS & NS & NS & NS \\
\hline Desafio $\mathrm{x}$ ácido & NS & NS & NS & NS \\
\hline
\end{tabular}

Médias seguidas por letras distintas na mesma coluna diferem entre si pelo teste de Tukey (5\%)

$\mathrm{O}$ pH dos cecos das aves aos 14 e aos 35 dias também foi influenciado pelos microrganismos, e o grupo controle apresentou $\mathrm{pH}$ inferior ao encontrado nos grupos contaminados $(\mathrm{P}<0,05)$. A presença de $\mathrm{pH}$ mais baixo sugere a fermentação de microrganismos presentes no sistema digestório com produção de ácidos graxos voláteis ${ }^{(19)}$, esses ácidos podem ser utilizados pelo frango como fonte energética, ainda que a porção final do intestino faça pouca absorção.

Foi possível verificar que a adição de ácidos orgânicos na ração reduziu o pH do intestino delgado aos 14 dias de idade $(\mathrm{P}<0,05)$. Nos demais períodos estudados, a adição de acidificantes não interferiu no pH do intestino delgado e dos cecos. Esses achados são condizentes com o mecanismo de ação dos ácidos orgânicos, visto que o efeito antibacteriano dos acidificantes é maior na parte anterior do sistema digestório (inglúvio/ventrículo) ${ }^{(20)}$ e os ácidos orgânicos lipossolúveis na forma indissociada, o que permite passar pela membrana celular dos microrganismos, dessa forma ocorre a inibição do crescimento microbioano. Sendo assim, não foram encontradas alterações nas porções inferiores do trato gastrintestinal. Entretanto, Santana et al. ${ }^{(21)}$ encontraram diferenças nos valores de $\mathrm{pH}$ cecal de frangos de corte que receberam acidificante (lactulose) em água para frangos de corte.

Para os resultados da contagem de oocistos de Eimeria tenella por grama de excretas após 5 a 11 dias da inoculação (Tabela 2), pode-se observar que a adição de ácidos orgânicos na ração não influenciou 
a contagem de oocistos do conteúdo cecal cinco e seis dias após a inoculação do protozoário. Entretanto, ocorreu redução do número de oocistos das excretas dos grupos que receberam ácidos orgânicos na ração diferindo $(\mathrm{P}<0,05)$ dos grupos que não receberam ácidos orgânicos a partir de sete dias após a inoculação até 11 dias.

Tabela 2. Contagem de oocistos por grama de excretas após 5 a 11 dias da inoculação de Eimeria tenella (expressa em Log) em frangos de corte desafiados com Salmonella Enteritidis e Eimeria tenella via oral e tratados com ração contendo ácidos orgânicos

\begin{tabular}{lccccccc}
\hline Ácido & \multicolumn{7}{c}{ Dias após a inoculação } \\
\hline & $\mathbf{5}$ & $\mathbf{6}$ & $\mathbf{7}$ & $\mathbf{8}$ & $\mathbf{9}$ & $\mathbf{1 0}$ & $\mathbf{1 1}$ \\
\hline Sem ácidos & 3,08 & 3,67 & $6,71 \mathrm{a}$ & $5,58 \mathrm{a}$ & $5,50 \mathrm{a}$ & $5,31 \mathrm{a}$ & $5,51 \mathrm{a}$ \\
Com ácidos & 3,01 & 3,32 & $4,83 \mathrm{~b}$ & $4,31 \mathrm{~b}$ & $4,07 \mathrm{~b}$ & $4,03 \mathrm{~b}$ & $4,04 \mathrm{~b}$ \\
Valor de P & 0,331 & 0,143 & 0,016 & 0,031 & 0,035 & 0,037 & 0,039 \\
CV (\%) & 7,10 & 13,64 & 1,97 & 8,31 & 8,79 & 6,31 & 11,10 \\
\hline
\end{tabular}

Médias seguidas por letras minúsculas distintas na mesma coluna diferem entre si pelo teste Tukey $(\mathrm{P}<0,05)$

A maior contagem de oocistos nas excretas aos sete dias após a inoculação ocorreu provavelmente devido à maior eliminação de oocistos pelas fezes neste período. Estes resultados são condizentes com Kawazoe ${ }^{(15)}$, quando citou que a infecção por Eimeria tenella se caracteriza por sangramento e espessamento da parede cecal no quinto e sexto dias após a infecção, com posterior eliminação de oocistos nas fezes, coincidindo com a maturação da segunda geração de esquizogonia. A diminuição do número de oocistos nas excretas dos grupos que receberam ácidos orgânicos na dieta provavelmente ocorreu pelo benefício à saúde intestinal das aves desses grupos proporcionado pela ação dos acidificantes, com diminuição da invasão bacteriana na mucosa cecal.

Com relação ao escore, nas lesões produzidas pela coccidiose nas paredes internas dos cecos aos 21 dias de idade observa-se que houve diferença $(\mathrm{P}<0,05)$ entre os tratamentos quando se avaliou as médias de lesões por coccidiose causadas pela Eimeria tenella (Tabela 3). As aves que receberam ração sem a adição de ácidos orgânicos apresentaram maior média de lesões aos 21 dias de idade, quando comparado ao tratamento que recebeu adição de acidificantes na ração.

Tabela 3. Escore de lesão por coccidiose no ceco de frangos de corte aos 21 dias de vida desafiados com Salmonella Enteritidis e Eimeria tenella via oral e tratados com ração contendo ácidos orgânicos

\begin{tabular}{|c|c|c|c|c|c|c|}
\hline & \multicolumn{5}{|c|}{ Escore de lesões } & \multirow[t]{2}{*}{ Média de lesões } \\
\hline Tratamento & $\mathbf{0}$ & 1 & 2 & 3 & 4 & \\
\hline $\mathrm{SE}+\mathrm{Et}$ com ácido & 0 & 2 & 4 & 0 & 0 & $4,83 \mathrm{a}$ \\
\hline $\mathrm{SE}+\mathrm{Et}$ sem ácido & 0 & 0 & 4 & 2 & 0 & $8,16 b$ \\
\hline $\mathrm{P}$ & & & & & & \\
\hline
\end{tabular}

Escore de lesão: 0 - sem lesões; 1 - lesões leves; 2 - lesões moderadas; 3 - lesões intensas; 4 - lesões severas e irreversiveis.

Médias seguidas por letras diferentes diferem entre si pelo teste Kruskal-Wallis (KW).

SE - Salmonela ENTERITIDIS; Et - Eimeria tenella

A provável causa para esses resultados é a mesma que justificou a redução no número de oocistos por grama de fezes observada nos tratamentos que receberam a adição de ácidos orgânicos na ração, ou seja, a melhoria na saúde intestinal proporcionada pela ação benéfica dos acidificantes no trato gastrintestinal. De acordo com Salazar et al. ${ }^{(22)}$, os resultados são consistentes em relação ao uso de acidificantes na melhora da capacidade do sistema digestivo das aves em metabolizar e utilizar o alimento e na modulação da microbiota intestinal. 
A pesquisa de Salmonella está apresentada na Tabela 4. Observou-se que do total de 16 aves dos grupos desafiados com Salmonella Enteritidis, foi identificada a presença de Salmonella em nove (56\%) e, destas nove aves, duas $(22,2 \%)$ receberam acidificantes na ração e morreram até os 15 dias de idade; três $(33,3 \%)$ não receberam acidificantes na ração e quatro aves $(44,4 \%)$ foram desafiadas com os dois patógenos em estudo e não receberam acidificantes na ração; uma ave destas quatro apresentou escore 4 de lesão por coccidiose. Foi investigada a presença de Salmonella nas sete aves que morreram do grupo não desafiados e não foi detectada presença de Salmonella nas amostras de órgãos analisados.

Em estudo com frangos de corte desafiados com Salmonella Enteritidis e tratados com ácidos orgânicos, Machado Júnior et al. ${ }^{(23)}$ verificaram que houve diminuição da contaminação e melhora no desempenho dos frangos. Nesse estudo, todas as aves dos grupos não desafiadas com Salmonella Enteritidis que foram necropsiadas apresentaram negatividade para a presença da bactéria nos órgãos analisados.

Tabela 4. Presença (\%) de Salmonella Enteritidis em frangos de corte fêmeas com 14, 21, 28 e 35 dias de idade desafiados com Salmonella Enteritidis e Eimeria tenella via oral e tratados com ração contendo ácidos orgânicos

\begin{tabular}{|c|c|c|c|c|c|}
\hline Tratamento/Idade & e 14 dias & 21 dias & 28 dias & 35 dias & Total \\
\hline \multicolumn{6}{|c|}{ Tonsilas cecais } \\
\hline $\mathrm{SE}$ c/ ácidos & $4 / 6 *(66,0 \%)$ & $0 / 6(0,0 \%)$ & $0 / 6(0,0 \%)$ & $0 / 6(0,0 \%)$ & $4 / 24(16,6 \%)$ \\
\hline SE s/ ácidos & $4 / 6(66,0 \%)$ & $4 / 6(66,0 \%)$ & $3 / 6(50,0 \%)$ & $2 / 6(33,0 \%)$ & $13 / 24(54,1 \%)$ \\
\hline $\mathrm{SE}+\mathrm{Et} \mathrm{c} /$ ácidos & $2 / 6(33,0 \%)$ & $2 / 6(33,0 \%)$ & $1 / 6(16,0 \%)$ & $1 / 6(16,0 \%)$ & $6 / 24(25,0 \%)$ \\
\hline $\mathrm{SE}+\mathrm{Et} \mathrm{s} /$ ácidos & $2 / 6(33,0 \%)$ & $5 / 6(83,0 \%)$ & $4 / 6(66,0 \%)$ & $3 / 6(50 \%)$ & $14 / 24(58,3 \%)$ \\
\hline \multicolumn{6}{|c|}{ Baço } \\
\hline $\mathrm{SE}$ c/ ácidos & $2 / 6(33,0 \%)$ & $1 / 6(16,0 \%)$ & $0 / 6(0,0 \%)$ & $0 / 6(0,0 \%)$ & $3 / 24(12,5 \%)$ \\
\hline SE s/ ácidos & $2 / 6(33,0 \%)$ & $2 / 6(33,0 \%)$ & $1 / 6(16,0 \%)$ & $2 / 6(33,0 \%)$ & $7 / 24(29,1 \%)$ \\
\hline $\mathrm{SE}+\mathrm{Et} \mathrm{c} /$ ácidos & $0 / 6(0,0 \%)$ & $1 / 6(16,0 \%)$ & $1 / 6(16,0 \%)$ & $0 / 6(0,0 \%)$ & $2 / 24(8,0 \%)$ \\
\hline $\mathrm{SE}+\mathrm{Et}$ s/ ácidos & $4 / 6(66,0 \%)$ & $3 / 6(50,0 \%)$ & $2 / 6(33,0 \%)$ & $2 / 6(33,0 \%)$ & $11 / 24(45,0 \%)$ \\
\hline
\end{tabular}

*Número de isolamentos positivos/número de amostras analisadas

$\mathrm{SE}$ - Salmonella Enteritidis; Et - Eimeria tenella

A Salmonella Enteritidis utilizada experimentalmente como agente desafiante foi capaz de promover a invasão do baço e colonizar o ceco das aves, persistindo por maior tempo nos grupos que também foram desafiados com Eimeria tenella. De acordo com Qin et al. ${ }^{(24)}$, a infecção das aves por Eimeria tenella pode determinar a permanência de Salmonella Enteritidis no intestino por um período mais longo, quando comparado com a infecção isolada pela SE, resultando em maior período de exposição da SE nas excretas, levando à reingestão e à reinfecção.

As aves desafiadas somente com Salmonella Enteritidis não apresentaram sinais clínicos, já quando desafiadas juntamente com Eimeria tenella os sinais clínicos observados entre 19 e 25 dias foram diarreia sanguinolenta, arrepiamento das penas e perda de peso, que provavelmente estavam

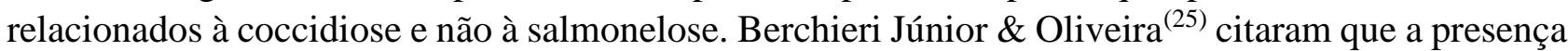
de sinais clínicos da salmonelose é comum em aves jovens e ocasional em adultas.

A detecção da Salmonella ssp. no baço ocorre após a ingestão oral com colonização do sistema digestório da ave, especialmente os cecos, e posteriormente penetra na mucosa epitelial, replicando dentro dos fagossomos, sobrevivendo, assim, dentro dos macrófagos, disseminando-se aos órgãos internos tais como o fígado, o baço e tecidos reprodutivos e estabelecendo um quadro de infecção sistêmica $^{(26)}$. 
Com relação ao tratamento com os ácidos orgânicos, foi possível observar que os grupos tratados obtiveram menores frequências de isolamento de SE no baço e tonsilas cecais do que os grupos que não receberam ácidos na ração, mesmo quando desafiados também com Eimeria tenella. Resultados semelhantes também foram encontrados por Banssan et al. $^{(27)}$, ao utilizarem acidificantes na ração para controlar $S$. Enteritidis e $S$. Typhimurium em frangos de corte, respectivamente.

De acordo com Min et al. ${ }^{(28)}$, a redução da invasão bacteriana celular no ceco pode ser justificada pela ação dos ácidos orgânicos em reduzir as bactérias ácido-intolerantes como Salmonella sp., com melhoria da digestibilidade da energia e da proteína, provavelmente pela redução da carga microbiana, diminuição na produção de aminas biogênicas e outros metabólitos, reduzindo o estímulo imune local, resultando na melhoria da saúde intestinal.

\section{Conclusão}

Em situação de desafio microbiológico, a adição de ácidos orgânicos (acético, fórmico e propiônico) na proporção de $4 \mathrm{~kg}$ por tonelada de ração pode ser recomendada, pois promoveu melhorias à saúde intestinal com reflexos positivos no controle da Salmonella Enteritidis juntamente com a Eimeria tenella.

\section{Referências}

1. Shinohara NKS, Barros VB, Jimenez SMC, Machado ECL, Dutra RAF, Lima Filho, JL. Salmonella spp., importante agente patogênico veiculado em alimentos. Ciência \& Saúde Coletiva, 2008;13(5), 1675-1683.

2. Andrade MA, Stringhini JH, Minafra-Rezende CS, Andrade L, Jayme VS. Histomorphometrical evaluation of gastrointestinal tract and performance of Ross broilers hatched from eggs inoculated with Salmonella Enteritidis phage type 4. Italian Journal of Animal Science. 2013; (12) 65-74.

3. Traesel CK, Lopes STA, Wolkmer P, Schmidt C, Santurio JM, Alves SH. Óleos essenciais como substituintes de antibióticos promotores de crescimento em frangos de corte: perfil de soroproteínas e peroxidação lipídica. Ciência Rural, 2011; 41(2), 278-284.

4. Toledo GSP, Costa PTC, Silva LP, Pinto D, Ferreira P, Poleto CJ. Desempenho de frangos de corte alimentados com dietas contendo antibiótico e/ou fitoterápico como promotores, adicionados isoladamente ou associados. Ciência Rural, 2007; 37(6), 1760-1764.

5. Yin G, Liu X, Zou J, Huang X, Suo X. Co-expression of reporter genes in the widespread pathogen Eimeria tenella using a double-cassette expression vector strategy. International Journal for Parasitology, 2011; 41(8), 813-816.

6. Fernandes JIM, Bortoluzzi C, Kosmann RC, Gottardo ET, Fernandes NLM. Suplementação dietética de levedura de cerveja e de minerais orgânicos sobre o desempenho e resposta imune em frangos de corte desafiados com a vacina de coccidiose. Ciência Rural, 2013;43(8), 1496-1502.

7. Li GQ, Kanus S, Xiang FY, Xiao LZ, CHEN HW, YE HJ. Isolation and selection of ionophore-tolerant Eimeria precocious lines: E. tenella, E. maxima and E. acervulina. Veterinary Parasitology, 2004; 119(4), 261276.

8. Vermeulen AN, Schaap DC, Schetters TP. Control of coccidiosis in chickens by vaccination. Veterinary Parasitology, 2001; 12, 13-20. 
9. Pickler L, Hayashi RM, Lourenço MC, Miglino LB, Caron LP et al. Avaliação microbiológica, histológica e imunológica de frangos de corte desafiados com Salmonella Enteritidis e Minnesota e tratados com ácidos orgânicos. Pesquisa Veterinária Brasileira, 2012; 32(1), 27-36.

10. Rostagno HS, Albino LFT, Donzele, JL et al. Tabelas brasileiras para aves e suínos: composição de alimentos e exigências nutricionais. Viçosa, MG: Universidade Federal de Viçosa, 2011.

11. Silva EN, Teixeira AS, Fialho ET, Bertechini AG, Souza PRI. Efeitos dos probióticos e antibióticos sobre as vilosidades e pH do trato gastrointestinal de frangos de corte. Ciência Agrotécnica, 2000;24 (Esp), 163-173.

12. GEORGIA POULTRY LABORATORY. Monitoring and detection of Salmonella in poultry and poultry environments. Oakwood: Georgia Poultry Laboratory, 1997;293.

13. BRASIL. Ministério da Agricultura, Pecuária e Abastecimento. Instrução Normativa ${ }^{\circ} 62$, de 26 de agosto de 2003. Oficializa os métodos analíticos oficiais para análises microbiológicas para controle de produtos de origem animal e água. Diário Oficial da União. Brasília, Seção 1, p.14, em 18/09/2003.

14. Andrade MA, Stringhini JH, Mesquita, AJ et al. Aspectos clínicos e anatomohistopatológicos de pintos de corte oriundos de ovos inoculados experimentalmente com Salmonella Enteritidis fagotipo 4. Ciência Animal Brasileira, 2009; 10(3), 909-917.

15. Kawazoe U. Coccidiose. In: Macari M.; Berchieri Jr, A. Doenças das aves. Campinas: FACTA, p. 391405, 2000.

16. Johnson J, Reid WM. Anticoccidial drugs: lesion scoring techniques in battery and floor-pen experiments with chickens. Experimental Parasitology, 1970; 28, 30-34.

17. SAS ${ }^{\circledR} 2000$. User's Guide: Statistics, Version $10^{\text {th }}$. SAS Institute Inc., Cary, NC.

18. Morgan NK, Walk CL, Bedford MR, Burtun EJ. The effect of dietary calcium inclusion on broiler gastrointestinal pH: Quantification and method optimization, Poultry Science, 2014; 93, 354-363.

19. Huang DS, Li DF, Xing JJ, Ma YX, Li ZJ. Effects of Feed Particle Size and Feed Form on Survival of Salmonella typhimurium in the Alimentary Tract and Cecal S. typhimurium Reduction in Growing Broilers. Poultry Science. v.8, p.831-836, 2006.

20. Bellaver C, Scheuermann G. Aplicações dos ácidos orgânicos na produção de aves de corte. AVESUI 2004. Disponível em http://www.cnpsa.embrapa.br/down.php?tipo=palestras\&cod_arqu ivo=13. Acessado em 23/05/2016.

21. Santana ES, Andrade MA, Café MB, Stringhini JH, Rocha TM, Jaime VS. Efeitos da lactulose na saúde gastrointestinal de frangos de corte experimentalmente inoculados com Salmonella enterica sorovar Typhimurium. Ciência Animal Brasileira, 2014; 15 (2), 187-194.

22. Salazar PCR, Albuquerque R, Takeara P, Trindade Neto EPA, Araújo LF. Efeito dos ácidos lático e butírico, isolados e associados sobre o desempenho e morfometria intestinal em frangos de corte. Brazilian Journal Veterinary Research Animal Science, 2008; 45(6) 463- 471.

23. Machado Junior P, Beirão BC, Fernandes Filho T, Lourenço MC, Joineau ML, Santin E, Caron LF. Use of blends of organic acids and oregano extracts in feed and water of broiler chickens to control Salmonella Enteritidis persistence in the crop and ceca of experimentally infected birds1. The Journal of Applied Poultry Research. 2014; 23(4), 671-82.

24. Qin, ZR, Fukata T, Baba E, Arakawa A. Effect of Eimeria tenella infection on Salmonella Enteritidis infection in chickens. Poultry Science, 1995, 74, 1-7.

25. Berchieri Júnior A, Oliveira GH. Salmoneloses aviárias. In: ANDREATTI FILHO, R.L. Saúde aviária e doenças. São Paulo: Roca, 2006, 96-111.

26. Bohez L, Gontois I, Ducatelle R, Pasmans F, et al. The Salmonella pathogenicity island 2 regulator ssrA

Cienc. anim. bras., Goiânia, v.20, 1-10, e-43084, 2019 
promotes reproductive tract but not intestinal colonization in chickens. Veterinary Microbiology, 2008; 126, 216-224.

27. Bassan JDL, Flores ML, Antoniazzi T, Biachiii E, Kuttel J, Trindade MM. Controle da infecção por Salmonella Enteritidis em frangos de corte com ácidos orgânicos e mananoligossacarídeo. Ciência Rural, 2008; 38(7), 234-245.

28. MIin JS, Lee SO, Jang A, Jo C, Lee M. Control of Microorganisms and Reduction of Biogenic Amines in Chicken Breast and Thigh by Irradiation and Organic Acids. Poultry Science, 2007; 86, 2034-2041. 